\title{
XXVI. An instrument for drawing conics
}

\section{J.R. Cotter M.A.}

To cite this article: J.R. Cotter M.A. (1904) XXVI. An instrument for drawing conics , Philosophical Magazine Series 6, 7:39, 274-276, DOI: 10.1080/14786440409463109

To link to this article: http://dx.doi.org/10.1080/14786440409463109

$$
\text { 册 Published online: } 15 \text { Apr } 2009 .
$$

Submit your article to this journal

Џll Article views: 4

Q View related articles ¿ 
imagine that a cylinder of hot lime, if it could be made airtight, would still be permeable to carbon dioxide. As a rule the disintegration produced by chenical action would prevent such partitions from being effective for any length of time, but still cases of this kind are possible and must therefore be considered.

The diffusion, which takes place in these cases by the gas particles being handed from one molecule to the other, follows in general the same kind of laws as those which have first been considered. There is, however, one very important difference conditioned by the fact that, the reaction being reversible, there is a definite dissociation pressure for each temperature. When the external pressure is $\geq$ the dissociation pressure, the whole of the superficial layer is turned into the compound, so that the solid cannot transmit a pressure greater than the dissociation pressure. Hence, if we start with a very high pressure on one side of the diaphragm and zero pressure on the other side, the pressure on the low pressure side will rise until it is equal to the dissociation pressure, when no further transference will take place. On the other hand, if the pressure on one side is always kept at zero, whilst that on the other side is capable of taking all values, then the rate of flow through will be a uniform function of the pressure up to the dissociation pressure, at which there will be a discontinuity, and the rate of flow will be independent of the pressure for all higher pressures.

XXVI. An Instrument for Drawing Conics. By J. R. СотteR, M.A., Assistant to the Professor of Experimental Physics, Trinity College, Dublin*.

$A^{P R O P O S}$ of Prof. Karl Pearson's article in the 'Philosophical Magazine' for February, I should like to mention that in the year 1894 I designed an instrument for drawing conics which has the advantage of always keeping the drawing-pen parallel to the direction of the curve. The compasses will draw any kind of conic, given the foci and a point on the curve. The accompanying figure is drawn from the actual instrument, but as it is only a rough home-made model it is faulty in construction.

$\mathrm{AGBF}^{\prime}$ is a rhombus formed of four equal and freely jointed flat brass rods. The corner A slides freely along the slot of the bar BC. FH is another flat brass bar pivoted

* Communicated by Prof. John Joly, F.R.S. 
to the rhombus at $\mathrm{G}$. It is slotted for a portion of its length and slides between the rhombus and $\mathrm{BC}$. A pencil-holder $\mathrm{P}$ moves in both slots together.

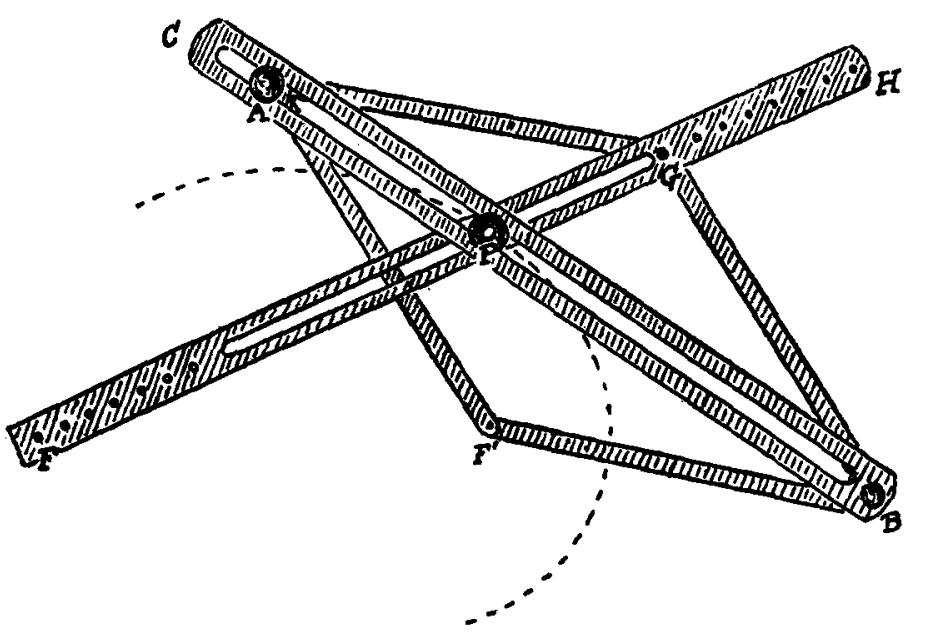

Two pins are driven into the drawing-board at the foci of the required conic and the pencil $P$ brought to a point on the curve. The corner $F^{\prime}$ of the rhombus is pivoted on one focus and FH turned round to the other focus, which can be fitted into one of the holes in FH. For an ellipse the second focus must be near the end $F$; for an hyperbola near the end $H$. Suppose that we wish to draw an ellipse, $F$ and $F^{\prime}$ being the foci. By elementary geometry $\mathrm{PF}^{\prime}=\mathrm{PG}$, therefore $\mathrm{FP}+\mathrm{PF}^{\prime}=\mathrm{FG}$, which is a fixed length on the rod. Thus $\mathrm{P}$ describes an ellipse. If the second focus were at $\mathrm{H}$, we should have $\mathrm{HP}-\mathrm{PF}^{\prime}=\mathrm{HG}=$ const., so that $\mathrm{P}$ would describe an hyperbola with $\mathrm{F}^{\prime}$ and $\mathrm{H}$ as foci.

In either case the line $\mathrm{AB}$ bisects the angle $\mathrm{FPF}^{\prime}$ externally (or $\mathrm{F}^{\prime} \mathrm{PH}$ internally) so that $\mathrm{AB}$ moves as a tangent to the curve. Thus if a drawing-pen were made to slide along $A B$ without turning, but turning freely in the slot of $\mathrm{FH}$, it would always keep tangential to the curve. This property is not possessed by the ingenious instrument described by Prof. Pearson. On the other hand, my instrument is open to the objection that it will only draw a little more than half an ellipse in one position. To describe the other half it must be reversed on the focal pins. Similarly, after drawing one branch of an hyperbola, it must be reversed on the pins to draw the other branch. 
It is clear from the figure that perfection of design has, in the model, been sacrificed for the sake of simplicity of construction. Instead of having holes bored in FH the slot should be extended to $\mathrm{F}$ and another slot cut between $\mathrm{G}$ and $\mathrm{H}$. A sliding focal pin could then be clamped in any position. Also the rhombus should have been shaped at the corners $A$ and $B$ so as always to leave sufficient space between the sides to allow of the pen $\mathrm{P}$ sliding right up to the corners, even if the rhombus is nearly closed.

To describe a parabola, $\mathrm{F}^{\prime}$ is made the focus, and $\mathrm{FH}$ is moved at right angles to itself, keeping it always parallel to its original direction. Under these circumstances $P$ describes a parabola, and $G$ its directrix. I made no provision in $\mathrm{my}$ model for drawing parabolas, hut I found that it would describe a very fair parabola if the flat end of $F$ were made to slide along a fixed ruler.

I have not previously published any description of these compasses, as I hoped some time to improve the design and get a good working instrument made.

XXVII. The Charges on Ions. By . ToHv S. Townsend, F.R.S., Wykeham Professor of Physics, Oxford*

THE relation between the charges on ions produced in gases by various methods is a matter of some importance, as the theory of electric currents in liquids and gases which is almost universally adopted is founded on the principle that all these small subdivisions of electricity with which the ions are charged are equal to or exact multiples of some charge which is absolutely fixed. The theory is supported by the phenomena which accompany the passage of electricity through liquids, and as is well known the charges on the ions are all exact multiples of the charge on the hydrogen ion in a liquid electrolyte. The theory also holds for gases ; and it can be proved that the charge on an ion produced by almost any of the known methods, in a gas, is identical with the charge on the hydrogen ion in a liquid electrolyte.

It is of interest to collect the results upon which this theory is founded, and to show to what degree of accuracy the atomic charge may be considered to be known.

If $\mathrm{E}$ is the charge on a hydrogen ion or atom in a liquid electrolyte, $\mathrm{N}$ the number of molecules per cubic centimetre

* Communicated by the Author. 